\title{
Time-varying and dose-dependent effect of long-term statin use on risk of type 2 diabetes: a retrospective cohort study
}

\author{
Eonji $\mathrm{Na}^{1}$, Sunyoung $\mathrm{Cho}^{2,3}$, Dae Jung Kim ${ }^{4}$ Junjeong Choi ${ }^{1}$ and Euna Han ${ }^{1^{*}}$ (1)
}

\begin{abstract}
Background: We evaluated the effect of statin use on new-onset type 2 diabetes among individuals without atherosclerotic cardiovascular disease (ASCVD) using nationally representative South Korean claims data (2002-2013, $\mathrm{N}=1,016,820)$.

Methods: A total of 13,698 patients (statin users 5273, non-statin users 5273) aged 40-74 years, newly diagnosed with dyslipidemia but without any history of diabetes or ASCVD, were selected in 2005. We followed up the final sample until 2013 and evaluated the cumulative incidence of type 2 diabetes. We used extended Cox regression models to estimate the time-varying adjusted hazard ratios of statin use on new-onset type 2 diabetes. We performed further analyses based on the cumulative defined daily dose of statin received per year to evaluate the degree of risk compared to non-statin users.

Results: Over the mean follow-up period of 7.1 years, 3034 patients developed type 2 diabetes; the number of statin users exceeded that of non-users, demonstrating that statin use significantly increased the risk of new-onset type 2 diabetes. The risk of new-onset type 2 diabetes differed among statin users according to CDDD per year (adjusted $\mathrm{HR}=1.31$ [95\% Cl 1.18-1.46] for less than $30 \mathrm{cDDD}$ per year; 1.58 [1.43-1.75] for 30-120 cDDD per year; 1.83 [1.62-2.08] for 120-180 cDDD per year; and 2.83 [2.51-3.19] for more than 180 cDDD per year). The diabetogenic effect of pitavastatin was not statistically significant, but the risk was the largest for atorvastatin. Long-term exposure ( $\geq 5$ years) to statins was associated with a statistically significant increase in the risk of new onset type 2 diabetes in all statin subtypes explored, with the highest magnitude for simvastatin ( $\mathrm{HR}=1.916,95 \% \mathrm{Cl} 1.647-2.228)$ followed by atorvastatin ( $\mathrm{HR}=1.830,95 \% \mathrm{Cl} 1.487-2.252)$.
\end{abstract}

Conclusions: Statin use was significantly associated with an increased risk of new-onset type 2 diabetes. We also found a dose-response relationship in terms of statin use duration and dose maintenance. Periodic screening and monitoring for incident type 2 diabetes may be warranted in long-term statin users.

Keywords: Statin, Type 2 diabetes, Time-varying survival analysis

\footnotetext{
*Correspondence: eunahan@yonsei.ac.kr

${ }^{1}$ Department of Pharmacy and Yonsei Institute of Pharmaceutical

Sciences Research, College of Pharmacy, Yonsei University, 162-1

Songdo-dong, Yeonsu-gu, Incheon, South Korea

Full list of author information is available at the end of the article
}

\begin{abstract}
Background
Statins, originally used in the treatment of dyslipidemia, are now the drugs of choice to prevent atherosclerotic cardiovascular disease (ASCVD) events following the release of the American College of Cardiology/American Heart Association (ACC/AHA)'s 2018 guidelines on the management of blood cholesterol [1]. This is because
\end{abstract}

(c) The Author(s) 2020. This article is licensed under a Creative Commons Attribution 4.0 International License, which permits use, sharing, adaptation, distribution and reproduction in any medium or format, as long as you give appropriate credit to the original author(s) and the source, provide a link to the Creative Commons licence, and indicate if changes were made. The images or other third party material in this article are included in the article's Creative Commons licence, unless indicated otherwise in a credit line to the material. If material is not included in the article's Creative Commons licence and your intended use is not permitted by statutory regulation or exceeds the permitted use, you will need to obtain permission directly from the copyright holder. To view a copy of this licence, visit http://creativeco mmons.org/licenses/by/4.0/. The Creative Commons Public Domain Dedication waiver (http://creativecommons.org/publicdomain/ zero/1.0/) applies to the data made available in this article, unless otherwise stated in a credit line to the data. 
dyslipidemia is itself an independent risk factor for ASCVD [2].

Statin use for primary prevention among patients who do not show any signs of ASCVD is controversial [3-5]. A recent large-scale experimental study reported a $27 \%$ higher risk of new-onset diabetes following statin use [6], which has prompted the United States Food and Drug Administration to add a risk of new-onset diabetes to statin labels [7]. However, some studies support the hypothesis that the lipid-lowering effects of statins for secondary prevention among patients with ASCVD outweigh their adverse metabolic effects $[8,9]$. Therefore, there is a need for further assessment of the risks of statin use in terms of new-onset diabetes, particularly considering the large number of patients in need of primary prevention of ASCVD and the widespread use of statins for that purpose [10].

The current study adds additional global epidemiological evidence of the effect of statin treatment on new-onset type 2 diabetes among individuals without cardiovascular disease using representative insurance claims data in South Korea. As epidemiological outcomes vary by demographic and socioeconomic circumstances, statins are not likely to pose the same degree of metabolic risk to all ethnicities. Indeed, the risk of new-onset diabetes associated with statin use is significantly higher in Asia [11, 12], where the prevalence of type 2 diabetes has increased twofold or more within the last decade [13]. Type 2 diabetes occurs even at a low BMI in Asia [14], leading to the development of a specialized approach for diabetes prevention and management becoming a top public health priority [14].

We also investigated the heterogeneity in the impact of statin use on new-onset type 2 diabetes by exposure period, intensities, and doses for all statins and by statin subtype. Despite its importance, there is no consensus regarding the intensity- and dose-dependent risk profile of statins with regard to new-onset diabetes. Given the potential increase in the use of intensive statin regimens based on the new ACC/AHA guidelines, it is important to conduct a detailed assessment of the association between statin use and new-onset type 2 diabetes.

\section{Methods}

\section{Study design and population}

We conducted a population-based retrospective cohort study using the National Health Insurance ServiceNational Sample Cohort. This dataset contains detailed data on the history of diagnoses and drug prescriptions as well as demographic and mortality-related information for 1,025,340 subjects from January 1, 2002 to December 31,2013 [15]. The target subjects of this study were those aged 40 to 74 and newly diagnosed with dyslipidemia with or without statin prescriptions. We defined the index date as the date of the first statin prescription for statin users and the date of a hyperlipidemia diagnosis for non-users. To identify prior disease status, we set the first 3 years (2002-2004) as the pre-index period. The index period was defined as January 1, 2005 to December 31, 2005 to minimize immortal time bias.

For the final sample, we first retained the 389,880 subjects aged 40 to 74 in 2005 from among the 1,025,340 participants enrolled in 2002. We then retained 294,805 subjects after applying the following exclusion criteria based on assessments made before the index period, that is, during 2002-2004: (1) patients who had been diagnosed with any type of diabetes; (2) patients who were previously diagnosed with any major type of ASCVD, including coronary artery disease, cerebrovascular disease, and peripheral artery disease; (3) patients who were prescribed any statins; (4) patients who had been diagnosed with dyslipidemia; (5) patients with inpatient records with any type of cancer; and (6) patients who were diagnosed with liver cirrhosis, which can cause safety concerns that can discourage the use of statins (see Additional file 1: Table S1 for specific diagnosis codes). We further restricted our sample to those who were diagnosed with dyslipidemia in 2005 , leaving only 17,074 subjects.

We then dichotomized the sample into statin users $(\mathrm{n}=8123)$ versus non-users $(\mathrm{n}=7907)$. Statin users were further restricted to the 6435 subjects who received their first statin prescription during the index period, who had at least two statin prescriptions per 6 months during the study period [16], and who were diagnosed with diabetes after first statin use during the index year. Non-users were also further restricted to the 7263 patients who had at least one ambulatory care visit but had not received any statin prescriptions during the study period and who were not diagnosed with type 2 diabetes before their dyslipidemia diagnosis during the index period. We adopted the greedy nearest neighbor algorithm in propensity score matching [17] to match statin users with non-users in a 1:1 ratio, using age, sex, and the Charlson Comorbidity Index (CCI) score as matching variables. Propensity score matching is a well-established technique to address possible confounding by indication and to maintain a balance between exposure and non-exposure groups [17]. After propensity score matching, 5273 statin users and 5273 non-users were analyzed (Fig. 1).

\section{Assessment of exposure to statins}

We identified atorvastatin, fluvastatin, lovastatin, rosuvastatin, simvastatin, pitavastatin, and pravastatin for analysis. Information on statin use was obtained from the dispensing data using the Anatomical Therapeutic 


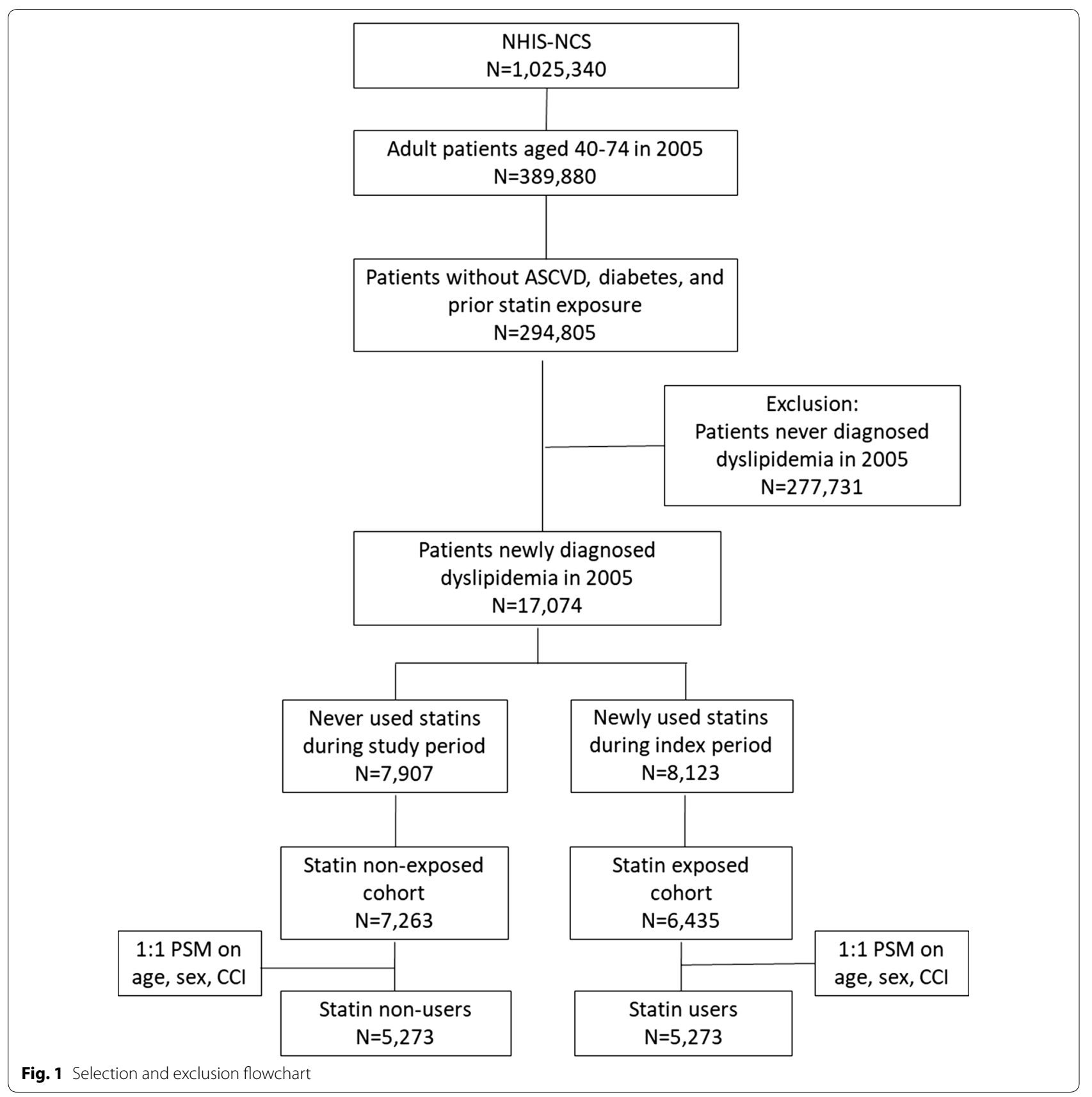

Chemical classification (Additional file 1: Table S2). We categorized statin use into three levels according to duration: less than 2 years, 2 to 5 years, and more than 5 years. Statins were further classified according to their standardized lipid-lowering effect based on the defined daily dose (DDD), which is an assumed maintenance dose per day for a drug used for its main indication in adult patients as defined by the World Health Organization [18]. We also calculated cumulative DDD
(cDDD) of statins per year by summing DDDs prescribed per year per individual, and further classified statin users by cDDD per year as follows: (1) less than $30 \mathrm{cDDD}$ per year, that is, used less than two consecutive months per year considering that clinicians often prescribe less than 0.5 DDD of statins in South Korea; (2) 30-120 cDDD per year, that is, 2 to 8 months; (3) 120-180 cDDD per year, that is, 8 months to a year; and (4) over $180 \mathrm{cDDD}$ per year, that is, a year of using over 1 DDD. 


\section{Identification of new-onset type 2 diabetes}

Follow-up for the target subjects ended when new-onset type 2 diabetes was initially identified or in the case of death. Otherwise, the endpoint of follow-up was set to December 31, 2013. The primary outcome of this study was incident cases of type 2 diabetes with International Classification of Disease, 10th revision diagnosis codes E11 and E14 (Additional file 1: Table S1). In a sensitivity analysis, patients who were diagnosed with new-onset type 2 diabetes in the first 1 month, 3 months, and 6 months after the index date were respectively removed from the sample to assess the possibility of surveillance bias. The incidence of type 2 diabetes was calculated as the number of patients with diabetes divided by the observed person-time.

\section{Covariate assessment}

Covariates included demographic variables (age and sex) and socioeconomic status variables (insurance premium level and urbanization of residence), all of which were defined at the index date. Age was classified into seven categories: 40-44 (reference group), 45-49, 50-54, $55-59,60-64,65-69$, and 70-74. The insurance premium level reported in deciles was determined by the household income and classified into six categories: $0-2$ (reference group), 3-4, 5-6, 7-8, 9, and 10. The capital and six metropolitan cities were classified as urban and the rest as rural, with the latter as the reference. We also controlled for baseline comorbidities and co-medications identified from 2002 to 2004. Baseline comorbidities at the index date included hypertension, prediabetes, liver disease, chronic renal disease, family history of diabetes, morbid obesity, and other metabolic diseases (Additional file 1: Table S1). The number of outpatient and inpatient records from 2002 to 2004 were controlled for as indicators of prior clinical evaluation. We also included the CCI as a composite comorbidity score [19]. Concomitant medications considered to affect blood glucose level, including fibrates, niacin, ACE inhibitors, angiotensin II receptor blockers, calcium channel blockers, thiazide diuretics, and corticosteroids, were controlled for in all estimations [2-22] (Additional file 1: Table S2).

\section{Statistical analysis}

We compared subjects' baseline characteristics based on statin use (statin users versus non-users) using the $t$ test for continuous variables and the Chi square test for categorical variables. We also assessed the appropriateness of matching using standardized difference statistics for matching (age, sex, and the CCI score) and other variables $[23,24]$. Small $(<10 \%)$ absolute values of the standardized difference statistics support the assumption of balance between the treatment groups [25]. We calculated the overall incidence per 1000 person-years. We conducted time-to-event analyses using the Cox proportional hazards model to estimate the association between statin use and new-onset type 2 diabetes. The underlying time scale was days until type 2 diabetes onset from the index date. We tested the proportional hazards assumption with $\log -\log$ survival curves and could not reject the proportionality in the risk over time. Therefore, we used extended Cox models instead of the basic Cox proportional hazards model to capture the changed hazard ratios (HRs) over the duration of statin use, which is time-varying based on the exposure duration in the model.

We estimated multivariate models adjusting for all of the aforementioned covariates as time-fixed factors (i.e., those measured at the index date). We generated adjusted Kaplan-Meier curves to compare the time to new-onset type 2 diabetes by statin use. We have also conducted an analysis of the diabetogenic risk of statins by statin subtype. Both unadjusted and adjusted HRs with 95\% confidence intervals (CI) were calculated. All statistical analyses were performed with SAS version 9.4 (SAS Institute, Cary, NC).

\section{Results \\ Characteristics of the study cohort}

Table 1 shows the baseline characteristics of the final sample. The mean follow-up duration was 6.83 years among statin users and 7.37 years among non-users. The leading comorbidity among statin users was hypertension ( $60.14 \%$ of statin users; $40.85 \%$ of non-users) while among non-users it was liver disease $(48.57 \%$ of statin users; $61.86 \%$ of non-users). The leading co-medication both in statin users and non-users was beta-blockers (24.73\% of statin users; $16.73 \%$ of non-statin users). The majority of the sample had a CCI of $0(72.65 \%$ of statin users; $71.91 \%$ of non-users). The mean cDDD of statins during the overall study period was 561.32 and the mean cDDD per year was 11.58. DDD and the cDDD per prescription by statin subtype based on the initial prescription are presented in Table 2.

\section{Study outcomes}

The cumulative incidence of type 2 diabetes is presented in Table 3. During follow-up, 3034 patients developed type 2 diabetes: 1871 statin users (61.67\%) and 1163 non-users (38.33\%). The overall incidence of type 2 diabetes was 40.52 per 1000 person-years (51.95 for statin users, 29.93 for non-users) (Table 3). When we defined diabetes more strictly as those prescribed anti-diabetic medication, the incidence of diabetes was reduced to 26.35 versus 10.09 per 1000 person-years for the statin 
Table 1 Baseline characteristics of the study population after propensity score matching

\begin{tabular}{|c|c|c|c|c|}
\hline \multirow[t]{2}{*}{ Variable } & \multicolumn{2}{|l|}{ Patients, No (\%) } & \multirow[t]{2}{*}{$p$-value } & \multirow{2}{*}{$\begin{array}{l}\text { The standardized } \\
\text { difference statistics }\end{array}$} \\
\hline & Statin group $(\mathrm{N}=5273)$ & $\begin{array}{l}\text { Non-statin Group } \\
(\mathrm{N}=5273)\end{array}$ & & \\
\hline Sex & & & $<0.0001$ & \\
\hline Male & $2288(43.39)$ & $2534(48.06)$ & & -9.4 \\
\hline Female & $2985(56.61)$ & $2739(51.94)$ & & 9.4 \\
\hline Age at entry & & & 0.2309 & \\
\hline $40-44$ & $544(10.32)$ & $551(10.45)$ & & -0.4 \\
\hline $45-49$ & $905(17.16)$ & $920(17.45)$ & & -0.8 \\
\hline $50-54$ & $1027(19.48)$ & $1006(19.08)$ & & 1.0 \\
\hline $55-59$ & $1003(19.02)$ & $971(18.41)$ & & 1.6 \\
\hline $60-64$ & $861(16.33)$ & $749(14.20)$ & & 5.9 \\
\hline $65-69$ & $570(10.81)$ & $642(12.18)$ & & -4.3 \\
\hline $70-74$ & $363(6.88)$ & $434(8.23)$ & & -5.1 \\
\hline Insurance premium level & & & 0.3051 & \\
\hline 1 & 669 (12.69) & 695 (13.18) & & -1.5 \\
\hline 2 & $743(14.09)$ & $724(13.73)$ & & 1.0 \\
\hline 3 & $808(15.32)$ & $867(16.44)$ & & -3.1 \\
\hline 4 & $1179(22.36)$ & $1200(22.76)$ & & -1.0 \\
\hline 5 & $782(14.83)$ & $774(14.68)$ & & 0.4 \\
\hline 6 & $1092(20.71)$ & $1013(19.21)$ & & 3.7 \\
\hline Urbanization of residence & & & 0.0004 & \\
\hline Urban & $2681(50.84)$ & $2499(47.39)$ & & 6.9 \\
\hline Rural & $2592(49.16)$ & $2774(52.61)$ & & -6.9 \\
\hline Charlson comorbidity index score & & & 0.1937 & \\
\hline 0 & $3831(72.65)$ & $3792(71.91)$ & & 1.7 \\
\hline 1 & $545(10.34)$ & $588(11.15)$ & & -2.6 \\
\hline 2 & $762(14.45)$ & $732(13.88)$ & & 1.6 \\
\hline$\geq 3$ & $135(2.56)$ & $161(3.05)$ & & -3.0 \\
\hline \multicolumn{5}{|l|}{ Comorbidity } \\
\hline Hypertension & $3171(60.14)$ & $2154(40.85)$ & $<0.0001$ & 39.3 \\
\hline Prediabetes & $217(4.12)$ & $248(4.70)$ & 0.1415 & -2.9 \\
\hline Liver disease & $2561(48.57)$ & $3262(61.86)$ & $<0.0001$ & -27.0 \\
\hline Metabolic disorders & $315(5.97)$ & $413(7.83)$ & 0.0002 & -7.3 \\
\hline Renal disease & $648(12.29)$ & $782(14.83)$ & 0.0001 & -7.4 \\
\hline Hypothyroidism & $261(4.95)$ & $361(6.85)$ & $<0.0001$ & -8.1 \\
\hline Family history of diabetes & $10(0.19)$ & $9(0.17)$ & 0.8184 & 0.4 \\
\hline Morbid obesity & $47(0.89)$ & $31(0.59)$ & 0.0690 & 3.5 \\
\hline $\begin{array}{l}\text { Number of outpatient visits in the previous } \\
3 \text { years, mean (SD) }\end{array}$ & $30.65(21.92)$ & $27.95(20.33)$ & $<0.0001$ & 7.1 \\
\hline $\begin{array}{l}\text { Number of hospitalizations in the previous } \\
3 \text { years, mean (SD) }\end{array}$ & $0.2712(0.94)$ & $0.3006(0.91)$ & 0.1038 & -2.4 \\
\hline \multicolumn{5}{|l|}{ Comedication } \\
\hline Fibrates & $208(3.94)$ & $117(2.22)$ & $<0.0001$ & 10 \\
\hline Niacin & $26(0.49)$ & $28(0.53)$ & 0.7849 & -0.5 \\
\hline Corticosteroids & $189(3.58)$ & $204(3.87)$ & 0.4406 & -1.5 \\
\hline \multicolumn{5}{|l|}{ Hypertension medications } \\
\hline Beta-blocker & $1304(24.73)$ & $882(16.73)$ & $<0.0001$ & 19.8 \\
\hline ACE inhibitor & $533(10.11)$ & $295(5.59)$ & $<0.0001$ & 16.8 \\
\hline ARB & $470(8.91)$ & $237(4.49)$ & $<0.0001$ & 17.7 \\
\hline $\mathrm{CCB}$ & $1249(23.69)$ & $791(15.00)$ & $<0.0001$ & 22.1 \\
\hline Thiazide & $1102(20.90)$ & 729 (13.83) & $<0.0001$ & 18.8 \\
\hline
\end{tabular}


Table 1 (continued)

$A R B$ angiotensin receptor blocker, $C C B$ calcium channel blocker

${ }^{\text {a }}$ Small $(<10 \%)$ absolute values of the standardized difference statistics support the assumption of balance between treatment groups

\begin{tabular}{lll}
$\begin{array}{l}\text { Table } 2 \text { Dose } \begin{array}{l}\text { of } \\
\text { on the initial prescription }\end{array} \\
\text { Statin subtype }\end{array}$ & Mean (SD) & subtype based \\
\cline { 2 - 3 } & $\begin{array}{l}\text { DDD of statin } \\
\text { per prescription }\end{array}$ & $\begin{array}{l}\text { Cumulative } \\
\text { DDD of statin } \\
\text { per prescription }\end{array}$ \\
\hline Total (5273) & $0.667(0.25)$ & $11.58(86.99)$ \\
Atorvastatin (1071) & $0.61(0.27)$ & $13.09(33.66)$ \\
Fluvastatin (59) & $1.15(0.31)$ & $8.83(12.79)$ \\
Lovastatin (771) & $0.444(0)$ & $4.19(5.71)$ \\
Pitavastatin (27) & $1(0)$ & $13.41(19.3)$ \\
Pravastatin (391) & $0.61(0.43)$ & $6.32(11.48)$ \\
Rosuvastatin (243) & $1.03(0.2)$ & $10.84(15.22)$ \\
Simvastatin (2711) & $0.71(0.19)$ & $13.95(119.13)$ \\
\hline
\end{tabular}

and non-statin groups, respectively (Additional file 1: Table S3).

The risk of type 2 diabetes increased both in the unadjusted and adjusted Cox regression models (adjusted $\mathrm{HR}=1.47$ [95\% CI 1.3-1.67] for less than 2 years of exposure; 1.72 [1.51-1.96] for 2 to 5 years of exposure; and 1.85 [1.62-2.1] for over 5 years of exposure) (Additional file 1: Table S4; Fig. 2).

The next model assessed whether the mean cumulative statin dosage per year was associated with the risk of new-onset type 2 diabetes. Patients with higher statin maintenance doses had a higher risk of new-onset type 2 diabetes. The risk of new-onset type 2 diabetes differed among statin users according to cDDD per year (adjusted $\mathrm{HR}=1.31$ [95\% CI 1.18-1.46] for less than $30 \mathrm{cDDD}$ per year; 1.58 [1.43-1.75] for 30-120 cDDD per year; 1.83 [1.62-2.08] for 120-180 cDDD per year; and 2.83 [2.513.19] for more than 180 cDDD per year (Additional file 1 : Table S5; Fig. 3).

The relationship did not substantially change and remained statistically significant regardless of whether we included subjects diagnosed with new-onset type 2 diabetes 1 month, 3 months, or 6 months from the index date. Taking the non-users as the reference, overall, the adjusted HRs of type 2 diabetes were higher in statin users, with upward patterns observed in groups with longer exposure periods. The results of the sensitivity analyses provided reassurance that our HRs were capturing a true association (Additional file 1: Table S6).

Further analyses by statin subtype indicate that the diabetogenic effect of pitavastatin was not statistically significant, but the risk was the largest for atorvastatin $(\mathrm{HR}=1.942$, 95\% CI 1.661-2.269) followed by rosuvastatin $(\mathrm{HR}=1.932,95 \% \mathrm{CI} 1.511-2.471)$. We have also added analyses of the impact of each statin subtype on T2D incidence by years of exposure. However, we noted that pitavastatin was prescribed for only 27 patients and the frequency for fluvastatin was only 59. Therefore, we have addressed the subgroup analyses by years of exposure except for pitavastatin and fluvastatin.

When the duration of exposure was grouped as three intervals ( $<2$ years, 2-5 years, and 5 years or longer), short-term statin exposure $(<2$ years $)$ was not associated with type 2 diabetes incidence in all statin subtypes explored. At the same time, long-term exposure ( $\geq 5$ years) to statins was associated with a statistically significant increase in the risk of new onset type 2 diabetes in all statin subtypes explored, with the highest magnitude for simvastatin $(\mathrm{HR}=1.916,95 \%$ CI 1.647-2.228) followed by atorvastatin $(\mathrm{HR}=1.830,95 \%$ CI $1.487-$ 2.252) (Table 4).

\section{Discussion}

The present study showed that long-term statin use can induce new-onset type 2 diabetes in South Korean patients with dyslipidemia, using a nationally representative real-world dataset from insurance claims. Several large-scale experimental studies have reported an

Table 3 Cumulative incidence by statin use status

\begin{tabular}{lll}
\hline Variables & Statin group $(\mathbf{N}=\mathbf{5 2 7 3})$ & Non-statin group (N=5273) \\
\hline Follow-up period (years), mean (SD) & $6.83(2.82)$ & 1871 \\
Incidence (persons) & $36,015.19$ & 1163 \\
Total person-years & $38,856.24$ \\
$\begin{array}{l}\text { Cumulative incidence rate (per 1 000 person-years), mean } \\
\quad( \pm S D)\end{array}$ & $51.95(36.77-88.49)$ & $29.93(22.32-45.38)$ \\
\hline
\end{tabular}




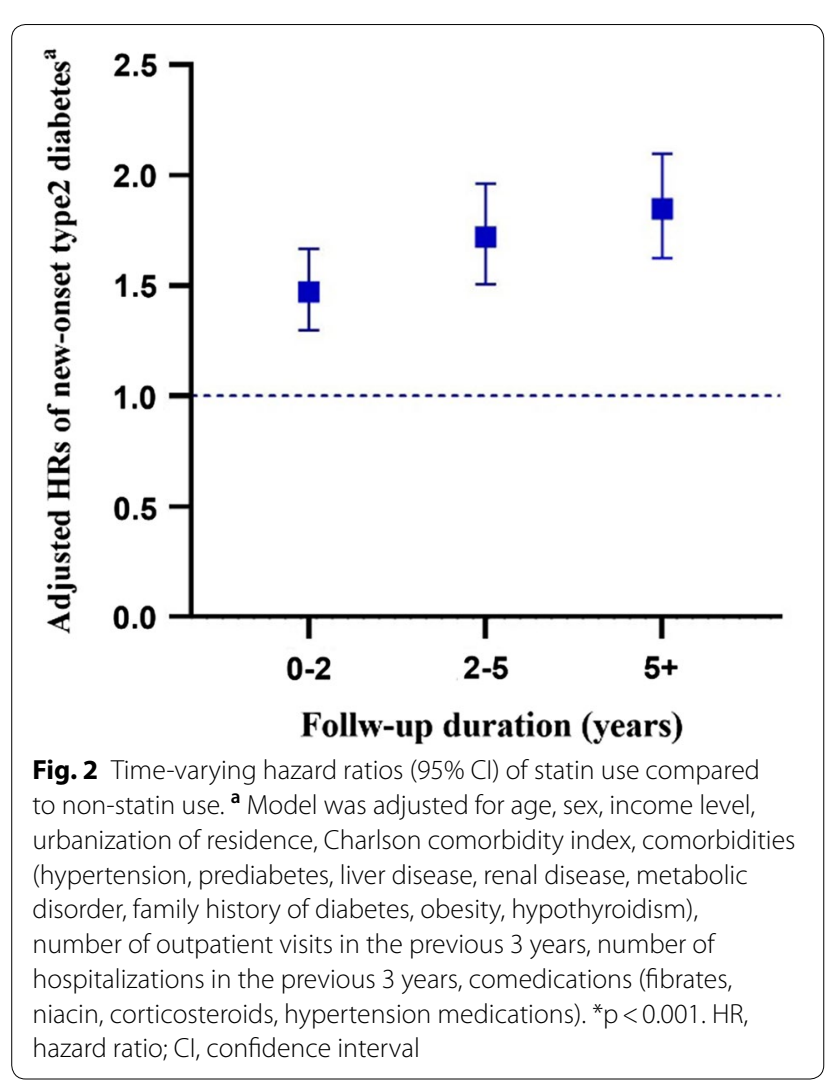

increased risk of new-onset diabetes in statin users, and a meta-analysis of randomized controlled trials (RCTs) confirmed this $(9 \%$ increased risk of new-onset type 2 diabetes) [26-29]. However, the rigorous selection of subjects for RCTs may lead to the exclusion of individuals at higher risk of adverse events. In addition, while diabetes is a chronic condition that may not be easily identified, most existing RCTs concluded before many patients could be diagnosed. Also, these analyses based on RCTs were post hoc, and thus, application in the real-world setting is limited.

We showed that the estimated magnitude of the diabetogenic risk of statins is greater in South Koreans than in western populations. Although observational studies in Canada, Italy, Ireland, and New Zealand have confirmed a significant increase in statin-induced diabetes [30-33], it is difficult to apply these results to Asia. Considering the different pharmaco-epidemic responses and characteristics of diabetes in Asians, the risk of new-onset diabetes following long-term statin use is likely to be heterogeneous among Asians. Furthermore, most previous studies on Asians have only used a single hospital center or health screening data that lacked external validity [11, 12, 34-36].

A recent study based on the national insurance claims data in South Korea showed that adults without diabetes at increased risk of coronary artery diseases had a modestly higher risk of incident diabetes after the initiation of statin therapy [37]. Similar to the Go (2020)' study [37], we estimated the risk of new-onset type 2 diabetes based on the database of national insurance claims, where all South Koreans are compulsory beneficiaries and all medical providers are compulsory providers [15].

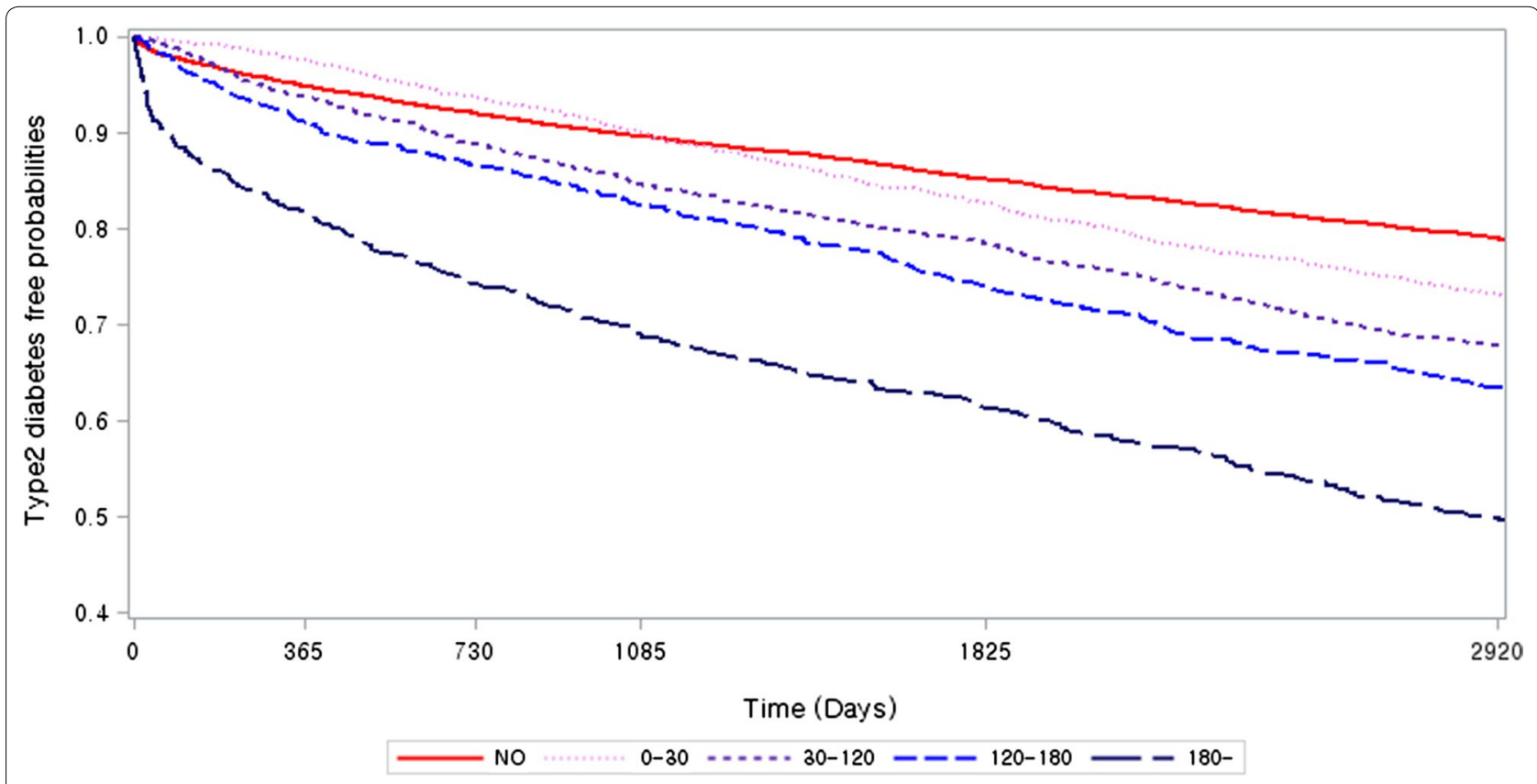

Fig. 3 Kaplan-Meier curves according to cumulative daily defined dose (cDDD) per year 
Table 4 Cox regression analysis on new-onset type2 DM according to years of exposure

\begin{tabular}{|c|c|c|c|c|c|c|c|c|}
\hline \multirow[t]{2}{*}{ (N) } & \multicolumn{4}{|c|}{ Unadjusted Hazard Ratio ${ }^{a}$} & \multicolumn{4}{|c|}{ Adjusted Hazard Ratio ${ }^{a}$} \\
\hline & HR & $95 \% \mathrm{Cl}$ & & p-value & $H R$ & $95 \% \mathrm{Cl}$ & & HR \\
\hline Non-statin (5273) & 1.000 & & & & 1.000 & & & \\
\hline Atorvastatin (1071) & 1.791 & 1.598 & 2.009 & $<0.0001$ & 1.942 & 1.661 & 2.269 & 1.942 \\
\hline$<2$ years $(137)$ & 1.027 & 0.846 & 1.248 & 0.7853 & 0.989 & 0.8 & 1.222 & 0.989 \\
\hline $2-5$ years $(127)$ & 1.007 & 0.822 & 1.234 & 0.9448 & 1.005 & 0.791 & 1.277 & 1.005 \\
\hline$\geq 5$ years $(807)$ & 1.907 & 1.563 & 2.327 & $<0.0001$ & 1.83 & 1.487 & 2.252 & 1.83 \\
\hline Lovastatin (771) & 1.847 & 1.624 & 2.101 & $<0.0001$ & 1.915 & 1.621 & 2.263 & 1.915 \\
\hline$<2$ years (103) & 1.07 & 0.862 & 1.328 & 0.5382 & 1.005 & 0.793 & 1.275 & 1.005 \\
\hline $2-5$ years (92) & 1.113 & 0.885 & 1.401 & 0.3599 & 1.068 & 0.826 & 1.382 & 1.068 \\
\hline$\geq 5$ years $(576)$ & 1.942 & 1.551 & 2.431 & $<0.0001$ & 1.846 & 1.458 & 2.337 & $<0.0 .0001$ \\
\hline Pravastatin (391) & 1.662 & 1.39 & 1.986 & $<0.0001$ & 1.758 & 1.429 & 2.164 & $<0.0001$ \\
\hline$<2$ years (42) & 0.914 & 0.677 & 1.234 & 0.5582 & 0.981 & 0.706 & 1.363 & 0.9093 \\
\hline $2-5$ years (50) & 1.256 & 0.946 & 1.666 & 0.1148 & 1.236 & 0.899 & 1.699 & 0.1911 \\
\hline$\geq 5$ years $(299)$ & 1.779 & 1.335 & 2.371 & $<0.0001$ & 1.633 & 1.211 & 2.203 & 0.0013 \\
\hline Rosuvastatin (243) & 1.723 & 1.381 & 2.15 & $<0.0001$ & 1.932 & 1.511 & 2.471 & $<0.0001$ \\
\hline$<2$ years $(32)$ & 0.931 & 0.653 & 1.328 & 0.6927 & 0.826 & 0.547 & 1.247 & 0.3635 \\
\hline $2-5$ years (30) & 1.727 & 1.198 & 2.491 & 0.0034 & 1.712 & 1.133 & 2.586 & 0.0107 \\
\hline$\geq 5$ years $(181)$ & 1.578 & 1.053 & 2.365 & 0.0271 & 1.587 & 1.051 & 2.398 & 0.0282 \\
\hline Simvastatin (2711) & 1.669 & 1.531 & 1.819 & $<0.0001$ & 1.794 & 1.567 & 2.055 & $<0.0001$ \\
\hline$<2$ years $(310)$ & 0.93 & 0.802 & 1.078 & 0.3341 & 0.912 & 0.776 & 1.071 & 0.2617 \\
\hline $2-5$ years $(290)$ & 0.988 & 0.846 & 1.155 & 0.8804 & 0.979 & 0.824 & 1.163 & 0.8103 \\
\hline$\geq 5$ years $(2111)$ & 1.967 & 1.701 & 2.274 & $<0.0001$ & 1.916 & 1.647 & 2.228 & $<0.0001$ \\
\hline
\end{tabular}

a Model was adjusted for age, sex, income level, urbanization of residence, Charlson comorbidity index, comorbidities (hypertension, prediabetes, liver disease, renal disease, metabolic disorder, family history of diabetes, obesity, hypothyroidism), number of outpatient visits in the previous 3 years, number of hospitalizations in the previous 3 years, comedications (fibrates, niacin, corticosteroids, hypertension medications). ${ }^{*} \mathrm{p}<0.001$. $\mathrm{HR}$, hazard ratio; $\mathrm{Cl}$, confidence interval

Therefore, our data reflect a representative sample of the national population and our results possess strong external validity.

Statins have demonstrated a heterogeneous potential to increase the incidence of diabetes $[38,39]$. A previous meta-analysis of RCTs regarding the primary prevention of ASCVD demonstrated a relatively low risk of newonset type 2 diabetes [40]. However, the risk of type 2 diabetes was statistically significant even after a relatively short period of statin exposure of a mean 254 days and median 1.9 years $[26,41]$. The small absolute risk of diabetes is outweighed by cardiovascular benefits in the short and medium term in individuals for whom statin therapy is recommended; long-term risk, however, has not fully been assessed in the previous literature [40]. Our study expands the literature by estimating the timedependent hazard levels to address the time-exposure interaction in the effect of statin use on new-onset type 2 diabetes. Our study showed that the inductive effect of new-onset type 2 diabetes is enhanced by the cumulative dose of statins per year. Short-term statin exposure ( $<2$ years) was not associated with new onset type 2 diabetes in all statin subtypes, whereas long-term exposure
( $\geq 5$ years) to statins was associated with a statistically significant increase in the risk of new onset type 2 diabetes in all statin subtypes.

Previous studies also have reported heterogeneous diabetogenic effects of statins by their subtypes [42]. For example, atorvastatin has been mostly reported to be more diabetogenic, whereas pitavastin is less so [43-45] or not diabetogenic [46]. Another study showed that even high-dose pitavastatin did not increase the risk of new onset of diabetes in patients at a high risk of developing diabetes during a 3-year follow-up [47]. We have addressed such variations not only for the overall use by statin subtypes but also by cumulative dosages per year and years of exposure for each subtype. Our findings are consistent with the previous studies in that pitavastatin did not show a statistically significant diabetogenic effect, whereas such an effect was the largest for atorvastatin followed by rosuvastatin.

Our study focused specifically on type 2 diabetes because that is the form clearly attributable to statin use. We also note that our identification of type 2 diabetes applies to a broad spectrum of severity, including mild diabetes without anti-diabetic medications. 
Most cases of incident diabetes in older patients are likely to be type 2 , and thus, we excluded patients aged under 40. Our restrictive design, part of a conservative approach, is likely to yield more robust outcomes than other approaches. Patients who are prescribed statins are more likely to be clinically examined or treated before the onset of type 2 diabetes, and thus have a higher chance of being diagnosed with type 2 diabetes than dyslipidemia patients without statin prescriptions. However, we adjusted for the frequency of outpatient visits to control for such detection bias.

The data used for the present study, which were extracted from insurance claims, have caveats. Our data did not include blood lipid profiles, fasting glucose levels, or hemoglobin A1c levels. Previous studies have suggested that low LDL cholesterol is associated with the onset of type 2 diabetes independent of statin use [48]. Some researchers have claimed that epicardial adipose tissue thickness at systole is a consistent independent predictor of new-onset diabetes mellitus in patients with coronary artery disease treated with high-intensity statins [49]. On the contrary, another study reported that even though statin therapy improved the lipid profile it had no effect on epicardial adipose tissue [50].

We also could not control for potential confounding factors such as BMI, health behaviors (e.g., smoking status, alcohol consumption, physical activity, or dietary intake), and genetic factors. A meta-analysis reported an increased metabolic risk in cases of LDL-C-lowering genetic variants [51]. However, we conducted propensity score matching to minimize selection bias. Considering the complexity of the relationships of metabolic diseases such as dyslipidemia, hypertension, and type 2 diabetes [52], we evaluated the effect of statin use on new-onset type 2 diabetes, controlling for dyslipidemia status and adjusting for hypertension. We also adjusted for a wide range of covariates including socioeconomic, demographic, and clinical factors, which have been reported to moderate the relationship between statin use and newonset type 2 diabetes [53, 54].

Caution should be used when applying our results to patients with different ASCVD risk profiles or histories because we measured risk of new-onset type 2 diabetes only for patients taking statins for primary prevention of ASCVD. Statin use for primary prevention of ASCVD is recommended to be based on individual decisions [1]. It has also been suggested that statin-dependent type 2 diabetes might be prognostically less adverse than diabetes unlikely to be induced by statins [30]. Future studies with longer follow-ups based on a prospective cohort study would further advance our understanding of the potential risks and benefits of stains for primary prevention of ASCVD.

\section{Conclusions}

The current study confirms the need for rigorous monitoring of patients taking statins, particularly those with established risk factors for diabetes onset. Our findings also suggest the necessity of taking the diabetogenicity of statins into consideration in clinical practice, emphasizing the concomitant need for dietary control and exercise.

\section{Supplementary information}

Supplementary information accompanies this paper at https://doi. org/10.1186/s12933-020-01037-0.

Additional file 1. Additional tables.

\section{Abbreviations}

ASCVD: Atherosclerotic cardiovascular disease; ACC/AHA: American College of Cardiology/American Heart Association; CCl: Charlson comorbidity index; DDD: Defined daily dose; cDDD: Cumulative defined daily dose; HR: Hazard ratio; RCTs: Randomized controlled trials.

\section{Acknowledgements}

None.

\section{Authors' contributions}

EH conceived the study, developed the study design, contributed to data analysis and data interpretation, and significantly revised the initial version of the manuscript. EN performed the literature search, contributed to the study design, performed data analysis and interpretation, generated figures and tables, and wrote the initial version of the manuscript. SYC, DJK, and JC contributed to the data interpretation and revised the entire manuscript. All authors approved the final version of the manuscript. EH is the guarantor of this work and, as such, had full access to all of the data in the study and takes responsibility for the integrity of the data and the accuracy of the data analysis.

\section{Funding}

E.H. was supported by the Korea National Research Foundation (Grant Number NRF-2019K2A9A2A08000108; NRF-2019R1A2C1003259). J.C. was supported by the Korea National Research Foundation (Grant Number NRF2018R1A6A1A03023718; NRF-2020R1A2C1003378). None of the funding sources were involved in the study design, data collection, data analysis, data interpretation, writing of the manuscript, or the decision to submit the manuscript for publication. None of the authors have been paid to write this article by a pharmaceutical company or other agency.

\section{Availability of data and materials}

The datasets used and/or analyzed during the current study are available from the corresponding author on reasonable request.

\section{Ethics approval and consent to participate}

This study was approved by the Ethics Institutional Review Board of Yonsei University (7001988-201903-HR-544-01E), which waived the requirement to obtain informed consent because of the de-identified nature of the data.

\section{Consent for publication}

Not applicable.

\section{Competing interests}

The authors declare that they have no competing interests.

\section{Author details}

${ }^{1}$ Department of Pharmacy and Yonsei Institute of Pharmaceutical Sciences Research, College of Pharmacy, Yonsei University, 162-1 Songdo-dong, Yeonsu-gu, Incheon, South Korea. ${ }^{2}$ Department of Pharmaceutical Medicine 
and Regulatory Sciences, College of Medicine and Pharmacy, Yonsei University, Incheon, South Korea. ${ }^{3}$ Integro Medi Lab Co., Ltd., Seoul, South Korea. ${ }^{4}$ Department of Endocrinology and Metabolism, Ajou University School of Medicine, Suwon, South Korea.

Received: 2 February 2020 Accepted: 9 May 2020 Published online: 16 May 2020

\section{References}

1. Grundy SM, Stone NJ, Bailey AL, Beam C, Birtcher KK, Blumenthal RS, et al. 2018 AHA/ACC/AACVPR/AAPA/ABC/ACPM/ADA/AGS/APhA/ASPC/NLA/ PCNA Guideline on the Management of Blood Cholesterol. Circulation. 2018;73(24):3168-209.

2. Nelson RH. Hyperlipidemia as a risk factor for cardiovascular disease. Prim Care. 2013;40(1):195-211.

3. Brugts JJ, Yetgin T, Hoeks SE, Gotto AM, Shepherd J, Westendorp RGJ, et al. The benefits of statins in people without established cardiovascular disease but with cardiovascular risk factors: meta-analysis of randomised controlled trials. BMJ. 2009;339:b2376.

4. Cholesterol Treatment Trialists C, Mihaylova B, Emberson J, Blackwell $L$, Keech A, Simes J, et al. The effects of lowering LDL cholesterol with statin therapy in people at low risk of vascular disease: meta-analysis of individual data from 27 randomised trials. Lancet. 2012;380(9841):581-90.

5. Pagidipati NJ, Navar AM, Mulder H, Sniderman AD, Peterson ED, Pencina MJ. Comparison of recommended eligibility for primary prevention statin therapy based on the US Preventive Services Task Force Recommendations vs the ACC/AHA Guidelines. JAMA. 2017;317(15):1563-7.

6. Macedo AF, Taylor FC, Casas JP, Adler A, Prieto-Merino D, Ebrahim S. Unintended effects of statins from observational studies in the general population: systematic review and meta-analysis. BMC Med. 2014;12:51.

7. Administration. USFaD. FDA drug safety communication: important safety label changes to cholesterol-lowering statin drugs. FDA Drug Safety Communication. 2012; <http://www.fda.gov/Drugs/DrugSafety/ucm29 3101.htm>

8. Keech A, Colquhoun D, Best J, Kirby A, Simes RJ, Hunt D, et al. Secondary prevention of cardiovascular events with long-term pravastatin in patients with diabetes or impaired fasting glucose - results from the LIPID trial. Diabetes Care. 2003;26(10):2713-21.

9. Rodriguez F, Maron DJ, Knowles JW, Virani SS, Lin S, Heidenreich PA. Association between intensity of statin therapy and mortality in patients with atherosclerotic cardiovascular disease. JAMA Cardiol. 2017;2(1):47-54.

10. Pender A, Lloyd-Jones DM, Stone NJ, Greenland P. Refining statin prescribing in lower-risk individuals: informing risk/benefit decisions. J Am Coll Cardiol. 2016:68(15):1690-7.

11. Chen CW, Chen TC, Huang KY, Chou P, Chen PF, Lee CC. Differential impact of statin on new-onset diabetes in different age groups: a population-based case-control study in women from an Asian country. PLOS ONE. 2013;8(8):e71817.

12. Rha SW, Choi BG, Seo HS, Park SH, Park JY, Chen KY, et al. Impact of statin use on development of new-onset diabetes mellitus in Asian Population. Am J Cardiol. 2016;117(3):382-7.

13. Ramachandran A, Snehalatha C, Shetty AS, Nanditha A. Trends in prevalence of diabetes in Asian countries. World J Diabetes. 2012;3(6):110-7.

14. Chan JN, MalikV, Jia W, et al. Diabetes in Asia: epidemiology, risk factors, and pathophysiology. JAMA. 2009;301 (20):2129-40.

15. Lee J, Lee JS, Park SH, Shin SA, Kim K. Cohort Profile: the National Health Insurance Service-National Sample Cohort (NHIS-NSC), South Korea. Int J Epidemiol. 2017:46(2):e15.

16. Ray WA. Evaluating medication effects outside of clinical trials: new-user designs. Am J Epidemiol. 2003;158(9):915-20.

17. Seeger JD, Williams PL, Walker AM. An application of propensity score matching using claims data. Pharmacoepidemiol Drug Saf. 2005;14(7):465-76.

18. Wertheimer Al. The defined daily dose system (DDD) for drug utilization review. Hosp Pharm. 1986;21 (3):233-4.

19. Charlson ME, Pompei P, Ales KL, MacKenzie CR. A new method of classifying prognostic comorbidity in longitudinal studies: development and validation. J Chronic Dis. 1987:40(5):373-83.
20. Sowers JR, Bakris GL. Antihypertensive therapy and the risk of type 2 diabetes mellitus. N Engl J Med. 2000;342(13):969-70.

21. Anyanwagu U, Idris I, Donnelly R. Drug-induced diabetes mellitus: evidence for statins and other drugs affecting glucose metabolism. Clin Pharmacol Ther. 2016;99(4):390-400.

22. D'Agostino RB. Propensity score methods for bias reduction in the comparison of a treatment to a non-randomized control group. Stat Med. 1998;17:2265-81.

23. Austin PC. Using the standardized difference to compare the prevalence of a binary variable between two groups in observational research. Commun Stat Simul Comput. 2009;38(6):1228-34.

24. Cohen J. Statistical power analysis for the behavioral sciences. Toronto: Academic Press Inc; 1977 [chapter 2].

25. Ridker PM, Pradhan A, MacFadyen JG, Libby P, Glynn RJ. Cardiovascular benefits and diabetes risks of statin therapy in primary prevention: an analysis from the JUPITER trial. Lancet. 2012;380(9841):565-71.

26. Shepherd J, Blauw GJ, Murphy MB, Bollen ELEM, Buckley BM, Cobbe SM, et al. Pravastatin in elderly individuals at risk of vascular disease (PROSPER): a randomised controlled trial. Lancet. 2002;360(9346):1623-30.

27. Sever PS, Dahlöf B, Poulter NR, Wedel H, Beevers G, Caulfield M, et al. Prevention of coronary and stroke events with atorvastatin in hypertensive patients who have average or lower-than-average cholesterol concentrations, in the Anglo-Scandinavian Cardiac Outcomes TrialLipid Lowering Arm (ASCOT-LLA): a multicentre randomised controlled trial. Lancet. 2003;361(9364):1149-58.

28. Group HC. MRC/BHF Heart Protection Study of cholesterol-lowering with simvastatin in 5963 people with diabetes: a randomised placebocontrolled trial. Lancet. 2003;361(9374):2005-16.

29. Carter AA, Gomes T, Camacho X, Juurlink DN, Shah BR, Mamdani MM. Risk of incident diabetes among patients treated with statins: population based study. BMJ. 2013;346:f2610.

30. Corrao G, Ibrahim B, Nicotra F, Soranna D, Merlino L, Catapano AL, et al. Statins and the risk of diabetes: evidence from a large populationbased cohort study. Diabetes Care. 2014;37(8):2225-32.

31. Zaharan NL, Williams D, Bennett K. Statins and risk of treated incident diabetes in a primary care population. Br J Clin Pharmacol. 2013:75(4):1118-24.

32. Currie O, Mangin D, Williman J, McKinnon-Gee B, Bridgford P. The comparative risk of new-onset diabetes after prescription of drugs for cardiovascular risk prevention in primary care: a national cohort study. BMJ Open. 2013;3(11):e003475.

33. Cho YJ, Choe EY, Lee YH, Seo JW, Choi YJ, Yun YJ, et al. Risk of diabetes in patients treated with HMG-CoA reductase inhibitors. Metabolism. 2015;64(4):482-8.

34. Yoon D, Sheen SS, Lee S, Choi YJ, Park RW, Lim HS. Statins and risk for new-onset diabetes mellitus: a real-world cohort study using a clinical research database. Medicine (Baltimore). 2016;95(46):e5429.

35. Kim J, Lee HS, Lee KY. Effect of statins on fasting glucose in non-diabetic individuals: nationwide population-based health examination in Korea. Cardiovasc Diabetol. 2018;17(1):155.

36. Go, et al. Statin therapy and risk of incident diabetes mellitus in adults with cardiovascular risk factors. Am J Cardiol. 2020;125:4534-41.

37. Preiss D, Seshasai SRK, Welsh P, Murphy SA, Ho JE, Waters DD, et al. Risk of incident diabetes with intensive-dose compared with moderatedose statin therapy a meta-analysis. JAMA. 2011;305(24):2556-64.

38. Navarese EP, Buffon A, Andreotti F, Kozinski M, Welton N, Fabiszak T, et al. Meta-analysis of impact of different types and doses of statins on new-onset diabetes mellitus. Am J Cardiol. 2013;111(8):1123-30.

39. Sattar N, Preiss D, Murray HM, Welsh P, Buckley BM, de Craen AJM, et al. Statins and risk of incident diabetes: a collaborative meta-analysis of randomised statin trials. Lancet. 2010;375(9716):735-42.

40. Mansi IA, English J, Zhang S, Mortensen EM, Halm EA. Long-term outcomes of short-term statin use in healthy adults: a retrospective cohort study. Drug Saf. 2016;39(6):543-59.

41. Ray K. Statin diabetogenicity: guidance for clinicians. Cardiovasc Diabetol. 2013;12(Suppl 1):S3. https://doi.org/10.1186/1475-2840-12-s1-s3.

42. Sabatine MS, Wiviott SD, Morrow DA, McCabe CH, Cannon CP. Highdose atorvastatin associated with worse glycemic control: a PROVE-IT TIMI 22 substudy [abstract]. Circulation. 2004;110(Suppl 3):834. 
43. Yamakawa T, Takano T, Tanaka S, Kadonosono K, Terauchi Y. Influence of pitavastatin on glucose tolerance in patients with type 2 diabetes mellitus. J Atheroscler Thromb. 2008;15(5):269-75.

44. Yokote K, Saito Y. CHIBA. Influence of statins on glucose tolerance in patients with type 2 diabetes mellitus: subanalysis of the collaborative study on hypercholesterolemia drug intervention and their benefits for atherosclerosis prevention (CHIBA study). J Atheroscler Thromb. 2009;16(3):297-8.

45. Vallejo-Vaz AJ, Kondapally Seshasai SR, Kurogi K, Michishita I, Nozue T, Sugiyama S, Tsimikas S, Yoshida H, Ray KK. Effect of pitavastatin on glucose, $\mathrm{HbA1c}$ and incident diabetes: a meta-analysis of randomized controlled clinical trials in individuals without diabetes. Atherosclerosis. 2015;241(2):409-18.

46. Jeong, et al. Incidence of new-onset diabetes with $1 \mathrm{mg}$ versus $4 \mathrm{mg}$ pitavastatin in patients at high risk of developing diabetes during a 3-year follow-up. Cardiovasc Diabetol. 2019;18:162.

47. Ndrepepa G, Cassese S, Xhepa E, Fusaro M, Laugwitz KL, Schunkert H, Kastrati A. Relation of hypocholesterolemia with diabetes mellitus in patients with coronary artery disease. Am J Cardiol. 2020;125(7):1026-32.

48. Kang, et al. Increased epicardial adipose tissue thickness is a predictor of new-onset diabetes mellitus in patients with coronary artery disease treated with high-intensity statins. Cardiovasc Diabetol. 2018;17:10.

49. Colom, et al. Associations between epicardial adipose tissue, subclinical atherosclerosis and high-density lipoprotein composition in type 1 diabetes. Cardiovasc Diabetol. 2018;17:156
50. Lotta LA, Sharp SJ, Burgess S, Perry JRB, Stewart ID, Willems SM, et al. Association between low-density lipoprotein cholesterol-lowering genetic variants and risk of type 2 diabetes: a meta-analysis. JAMA. 2016;316(13):1383-91.

51. Lotta LA, Stewart ID, Sharp SJ, Day FR, Burgess S, Luan J, et al. Association of genetically enhanced lipoprotein lipase-mediated lipolysis and low-density lipoprotein cholesterol-lowering alleles with risk of coronary disease and type 2 diabetes. JAMA Cardiol. 2018;3(10):957-66.

52. Srikanth S, Deedwania P. Management of dyslipidemia in patients with hypertension, diabetes, and metabolic syndrome. Curr Hypertens Rep. 2016;18(10):76

53. Waters DD, Ho JE, Boekholdt SM, DeMicco DA, Kastelein JJ, Messig M, et al. Cardiovascular event reduction versus new-onset diabetes during atorvastatin therapy: effect of baseline risk factors for diabetes. J Am Coll Cardiol. 2013;61(2):148-52.

54. Mason JM, Dickinson HO, Nicolson DJ, Campbell F, Ford GA, Williams B. The diabetogenic potential of thiazide-type diuretic and betablocker combinations in patients with hypertension. J Hypertens. 2005;23(10):1777-81.

\section{Publisher's Note}

Springer Nature remains neutral with regard to jurisdictional claims in published maps and institutional affiliations.
Ready to submit your research? Choose BMC and benefit from:

- fast, convenient online submission

- thorough peer review by experienced researchers in your field

- rapid publication on acceptance

- support for research data, including large and complex data types

- gold Open Access which fosters wider collaboration and increased citations

- maximum visibility for your research: over 100M website views per year

At BMC, research is always in progress.

Learn more biomedcentral.com/submissions 